\title{
Low-Temperature Luminescence and Thermally Stimulated Luminescence of BeO:Mg Single Crystals
}

Article in Physics of the Solid State · January 2018

DOI: $10.1134 / \mathrm{S} 106378341801016 \mathrm{X}$

CITATIONS

0

3 authors, including:

\section{Igor N. Ogorodnikov}

Ural Federal University

204 PUBLICATIONS 952 CITATIONS

SEE PROFILE
READS

72

Maxim D. Petrenko

Ural Federal University

4 PUBLICATIONS 6 CITATIONS

SEE PROFILE

Some of the authors of this publication are also working on these related projects: 


\title{
Low-Temperature Luminescence and Thermally Stimulated Luminescence of $\mathrm{BeO}: \mathrm{Mg}$ Single Crystals
}

\author{
I. N. Ogorodnikov, M. D. Petrenko, ${ }^{*}$ and V. Yu. Ivanov \\ Ural Federal University, Yekaterinburg, 620002 Russia \\ *e-mail: md.petrenko@urfu.ru \\ (Received May 25, 2017; in final form, June 28, 2017)
}

\begin{abstract}
Luminescence and thermally stimulated luminescence (TL) of $\mathrm{BeO}: \mathrm{Mg}$ crystals are studied at $T=6-380 \mathrm{~K}$. The TL glow curves and the spectra of luminescence $(1.2-6.5 \mathrm{eV})$, luminescence excitation, and reflection $(3.7-20 \mathrm{eV}$ ) are obtained. It is found that the introduction of an isovalent magnesium impurity into $\mathrm{BeO}$ leads to the appearance of three new broad luminescence bands at $6.2-6.3,4.3-4.4$, and 1.9-2.6 eV. The first two are attributed to the radiative annihilation of a relaxed near-impurity $(\mathrm{Mg})$ exciton, the excited state of which is formed as a result of energy transfer by free excitons. The impurity VUV and UV bands are compared with those for the intrinsic luminescence of $\mathrm{BeO}$ caused by the radiative annihilation of self-trapped excitons (STE) of two kinds: the band at $6.2-6.3 \mathrm{eV}$ of $\mathrm{BeO}: \mathrm{Mg}$ is compared with the band at $6.7 \mathrm{eV}\left(\mathrm{STE}_{1}\right)$ of $\mathrm{BeO}$, and the band at $4.3-4.4 \mathrm{eV}$ is compared with the band at $4.9 \mathrm{eV}\left(\mathrm{STE}_{2}\right)$ of $\mathrm{BeO}$. In the visible region, the luminescence spectrum is due to a superposition of intracenter transitions in an impurity complex including a magnesium ion. The manifestation of X-ray induced luminescence bands at $T=6 \mathrm{~K}$ in $\mathrm{BeO}: \mathrm{Mg}$ indicates their excitation during band-to-band transitions and in recombination processes. The energy characteristics of the impurity states in $\mathrm{BeO}: \mathrm{Mg}$ are determined; the effect of the isovalent impurity on the fluctuation rearrangement of the $\mathrm{BeO}: \mathrm{Mg}$ structure in the thermal transformation region of $\mathrm{STE}_{1} \rightarrow \mathrm{STE}_{2}$ is revealed.
\end{abstract}

DOI: $10.1134 / \mathrm{S} 106378341801016 \mathrm{X}$

\section{INTRODUCTION}

Impressive success in the study of the processes of radiative and nonradiative decays of low-energy electronic excitations in alkali halide crystals $[1,2]$ served as a powerful stimulus for numerous studies of other crystalline systems. Among them, it is necessary to distinguish a class of wide-gap oxides that have both unique physicochemical and optical properties and radiationoptical stability. However, even the nearest analogue of alkali halide crystals, cubic $\mathrm{MgO}$, demonstrated significant differences in the relaxation processes of lowenergy electronic excitations [3-5]. Even more differences from alkali halide crystals were revealed in studies of crystalline systems with reduced symmetry.

For example, the study of luminescence of hexagonal beryllium oxide has a long history. As early as 1881, Crookes first observed and described a bright radioluminescence of $\mathrm{BeO}$ powder [6]. However, only seventy years later, the first spectroscopic studies of broadband ultraviolet (UV) luminescence of $\mathrm{BeO}$ were performed at room temperature $[7,8]$ and the temperature of liquid air [9]. The appearance of bulk optical $\mathrm{BeO}$ single crystals $[10,11]$ stimulated detailed studies of the crystallographic structure, luminescence, and electronic excitations in $\mathrm{BeO}$.

Beryllium oxide crystals belong to the hexagonal system (space group $P 6_{3} m c$ ) and crystallize in a wurtzitetype structure, which is two interpenetrating hexagonal

* md.petrenko@urfu.ru sublattices of oxygen and beryllium ions. Anions thus form an almost densest hexagonal package. The basis of the structure consists of clusters $\left[\mathrm{BeO}_{4}\right]^{6-}$, representing four anions, located at the tops of a tetrahedron and surrounding the cation. It is important to note the off-center position of the cation in the tetrahedron and the decrease of the point symmetry group of the regular lattice sites to $C_{3}$. The lattice parameters $(\AA)$ are $a=2.69773 \pm 0.00007$ and $c=4.37767 \pm 0.00008$ [12].

The efforts of many scientific teams established the fact, in particular, that the low-energy fundamental absorption edge of $\mathrm{BeO}$ is located in the energy region above $9.0 \mathrm{eV}$ [13]. In the reflection spectra of undoped $\mathrm{BeO}$ single crystals at $T=77 \mathrm{~K}$, a developed edge exciton structure was found that includes the lowestenergy peaks at $E_{n=1}=10.455$ and $E_{n=2}=10.585 \mathrm{eV}$ [14]. These peaks were attributed to the creation of excitons at the $\Gamma$-point of the Brillouin zone, and it was determined on the basis of these data that the energy gap of an undoped $\mathrm{BeO}$ single crystal at $T=77 \mathrm{~K}$ is $E_{g}=10.63 \mathrm{eV}$ [12]. Subsequently, the spectra of nonrelaxed excitons have been studied by means of techniques of synchrotron spectroscopy using oriented samples of BeO single crystals [15-17]. As a result, it was demonstrated that the energy position of the exciton absorption peaks in various $\mathrm{BeO}$ crystals could vary within small limits, depending on the orientation of the crystal relative to the polarization of the exciting radiation. The wide bands at 4.9 and $6.7 \mathrm{eV}$ in the spectrum of the intrinsic luminescence of $\mathrm{BeO}$ are interpreted as the radiative decay of two kinds of self-trapped excitons $\left(\mathrm{STE}_{1}\right.$ and $\left.\mathrm{STE}_{2}\right)$ [18], differing in the configuration of the hole core, that is, a small-radius polaron of the $\mathrm{O}^{-}$ ion type in the local fragment of the crystal lattice. The 
spectroscopic properties of these intrinsic luminescence bands of undoped $\mathrm{BeO}$ single crystals have been studied in detail in [19].

The possibilities of practical application of beryllium oxide are more often considered in connection with the development of radiation detectors. In particular, undoped $\mathrm{BeO}$ single crystals were studied as a working medium for a fast inorganic scintillator [20, 21]. However, ceramics, powders, thin films, and other products of $\mathrm{BeO}$, rather than crystalline $\mathrm{BeO}$, attract the greatest attention for practical applications. There is a huge amount of various publications on the practical aspects of $\mathrm{BeO}$ application. Not being able to quote (due to large amount) these sources, from all the variety of published results, we mention only a classical collective monograph [22] as an example. In the present paper, we focus on single crystals of $\mathrm{BeO}$.

For $\mathrm{BeO}$ single crystals, a number of reviews on point defects $[23,24]$ and the relaxation of low-energy electronic excitations [25-27] are known. In particular, it has been shown that in view of the crystallographic and crystallochemical characteristics, beryllium oxide has a small isomorphic capacity with respect to impurity substitutional ions; the level of occurrence of the most probable substitutional impurities ( $\mathrm{Li}, \mathrm{B}, \mathrm{Al})$ in deliberate doping of $\mathrm{BeO}$ single crystals hardly exceeds the background level; nevertheless, even such impurity concentrations substantially change the optical and luminescent properties of $\mathrm{BeO}$ [12].

The results of early studies performed by luminescence spectroscopy [28-30] and electron paramagnetic resonance (EPR) $[28,31]$ indicate the effect of isovalent cations introduced during the growing process on the optical and luminescent properties of $\mathrm{BeO}$. Being an isovalent impurity, $\mathrm{Zn} 2+$ ion upon introduction into the $\mathrm{BeO}$ lattice should create shallow local levels in the forbidden band and actively manifest itself in recombination processes. However, because $\mathrm{Be}^{2+}$ and $\mathrm{Zn}^{2+}$ have almost the same values of the second ionization potentials $(18.21$ and $17.96 \mathrm{eV})$, it is difficult to unequivocally predict what charge carriers will be captured at these shallow levels.

A recent paper [32] presents the results of a lowtemperature spectroscopic study of the manifestations of shallow impurity states due to the impurity of zinc in $\mathrm{BeO}: \mathrm{Zn}$ crystals. We do not know any data concerning a similar study of the impurity states of magnesium ions in $\mathrm{BeO}: \mathrm{Mg}$ single crystals. At the same time, for a 'mirror' crystalline system like a cubic crystal $\mathrm{MgO}$ doped with isovalent $\mathrm{Be}^{2+}$ ions, extensive data on luminescence [33, 34], color centers [35], and paramagnetic centers [36-38] have long been obtained.

The purpose of this work is to study the luminescence and thermoluminescence properties of $\mathrm{BeO}: \mathrm{Mg}$ single crystals over a wide temperature range from 6 to $380 \mathrm{~K}$ and energy intervals of 1.2-6.5 eV (luminescence spectra) and 3.7-20 eV (reflection and luminescence excitation spectra).

\section{EXPERIMENTAL}

In this work, single crystals of beryllium oxide of two types were studied: initial undoped crystals $(\mathrm{BeO})$ and beryllium oxide crystals deliberately doped (0.05 at \%) with an isovalent magnesium impurity (BeO:Mg). The level of dopant concentration was selected based on two conditions. On the one hand, it is selected sufficiently low to avoid the effect of the dopant on the lattice parameters and the width of the forbidden band of the crystal. On the other hand, it is high enough to study the optical and luminescent properties of impurity states in BeO:Mg.

All single crystals of beryllium oxide investigated in this work were grown in the Institute of Geology and Mineralogy, Siberian Branch, Russian Academy of Sciences (Novosibirsk, Russia). The $\mathrm{BeO}$ and $\mathrm{BeO}: \mathrm{Mg}$ crystals were grown by a melt-solution method, in which sodium tungstate was used as a flux agent. Other details of growing technology are consistent with previously published data [12]. Doping with a magnesium impurity was carried out during the growth of the crystal by adding an appropriate amount of magnesium oxide to the charge. Samples for spectroscopic examination were prepared in the form of plane-parallel plates with dimensions of $7 \times 7 \times 2 \mathrm{~mm}$. The large plane of the samples represented a natural growth face for undoped $\mathrm{BeO}$ crystals and a polished face for $\mathrm{BeO}: \mathrm{Mg}$ crystals.

Low-temperature luminescence under X-ray excitation (X-ray induced luminescence (XRL)) and thermally stimulated luminescence (TL) were studied at the Laboratory of Solid State Physics of the Ural Federal University (Yekaterinburg, Russia). The sample was placed in a chamber of a fast-response vacuum cryostat with optical quartz windows. The residual gas pressure after cryostat evacuation did not exceed $10^{-4} \mathrm{~Pa}$. The Xray spectra were recorded upon excitation by an unfiltered X-ray radiation of an URS-0.02 laboratory source (Cu-anticathode; anode voltage $U_{a}=40 \mathrm{kV}$; tube current $I_{a}=0.4 \mathrm{~mA}$ ) at temperatures $T=6$ and $293 \mathrm{~K}$. An MDR-23 high-resolution grating monochromator and an R6356 photomultiplier tube (PMT) (Hamamatsu) were used as the recording system. The inverse linear dispersion of the monochromator was $0.3 \mathrm{~nm} / \mathrm{mm}$; the spectra were recorded in steps of $1 \mathrm{~nm}$. Before recording the TL glow curve, the sample was placed in a measuring chamber, the vacuum cryostat was evacuated to $10^{-4} \mathrm{~Pa}$, then the sample was cooled to a temperature of $T_{0}=6 \mathrm{~K}$ and irradiated with X-ray radiation of a laboratory source for $20 \mathrm{~min}$. After completion of irradiation, the sample was held for several minutes at temperature $T_{0}$, and then the TL glow curves were recorded in the temperature range from 6 to $380 \mathrm{~K}$ with linear heating rate of $0.1 \mathrm{~K} / \mathrm{s}$. The TL recording system consisted of a FEU-130 photoelectric multiplier operating in the spectral-integral mode $(1.2-6.2 \mathrm{eV})$. In the graphical representation, each experimental curve (the XRL spectrum or the TL glow curve) was normalized in in- 
tensity to unity at the observed maximum. In the case of representing several curves on one diagram, the same constant normalizing factor, corresponding to the normalization of one of the curves to unity, was used for all curves. The only exception is the diagram with an overview TL glow curve, in which a semi-logarithmic scale is used for better viewing.

Photoluminescence (PL) spectra, photoluminescence excitation (PLE) spectra, and reflection spectra were studied under selective photoexcitation by synchrotron radiation at the SUPERLUMI experimental station of the HASYLAB laboratory (German Electron Synchrotron (DESY), Hamburg, Germany) [39]. A continuous-flow helium cryostat was used as the sample chamber, ensuring a degree of vacuum of no worse than $5 \times 10^{-8} \mathrm{~Pa}$. Samples were placed on the crystal holder of the cryostat and after evacuation cooled to a temperature of $T=10 \mathrm{~K}$. The primary monochromator with an aluminum-coated diffraction grating (4-20 eV) enabled a spectral resolution of $0.32 \mathrm{~nm}$. Luminescence in the visible and ultraviolet (UV) ranges was recorded using a high-aperture grating monochromator (a $0.5-\mathrm{m}$ Czerny-Turner scheme) and an R2059 photomultiplier type (Hamamatsu). In the vacuum UV (VUV) region, the luminescence was recorded with a VUV monochromator (a 0.5-m Seya-Namioka scheme) and an R1460 PM photomultiplier. Simultaneously with the recording of the PLE spectrum, a spectrum of reflection from the sample (angle of incidence $17.5^{\circ}$ ) was measured. To normalize the PLE spectra by an equal number of exciting photons at each point of the spectrum, we used sodium salicylate that is a phosphor having a constant quantum yield in the investigated spectral region.

\section{RESULTS}

\subsection{Low-Temperature Luminescence}

The XRL spectra of a BeO:Mg crystal, measured at 6 and $293 \mathrm{~K}$, are presented in Fig. 1. The spectra are normalized to a conventional intensity unity recorded at $293 \mathrm{~K}$ at the observed maximum at $4.6 \mathrm{eV}$. Three groups of luminescence bands are distinguished in the spectrum, which differ in origin and spectral properties. For convenience of discussion, all the observed luminescence bands in Fig. 1 are conditionally numbered with Roman numerals from I to VI.

In the XRL spectrum, two partially overlapping broad photoluminescence bands dominate: at 4.6 (IV) and $4.9 \mathrm{eV}(\mathrm{V})$, located in the UV region of the spectrum. The full width at the half-maximum (FWHM) for the observed UV band is $1.27 \mathrm{eV}$ at room temperature and $1.31 \mathrm{eV}$ at $T=6 \mathrm{~K}$. The intensity of the UV band at $T=6 \mathrm{~K}$ is approximately $3 / 4$ of that recorded at room temperature. These facts indirectly indicate, first, the complex nature of the dominant UV band (IV) +

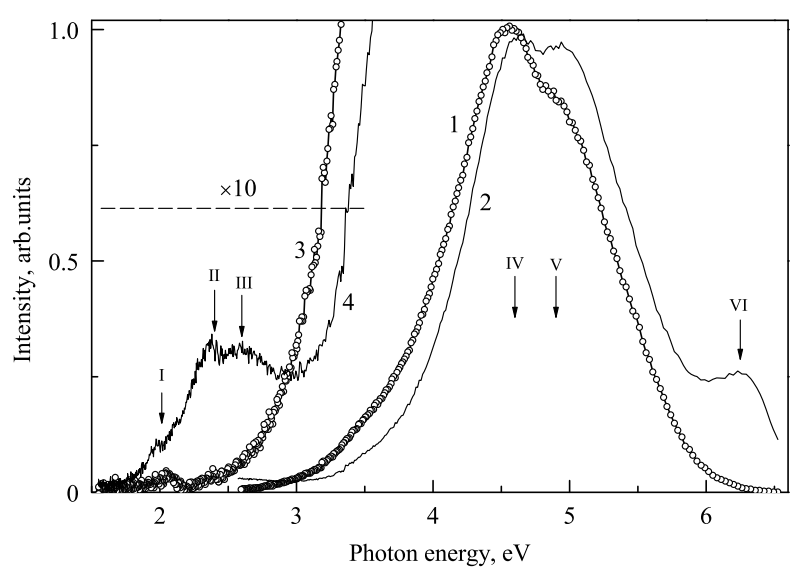

Figure 1. Luminescence spectra of $\mathrm{BeO}: \mathrm{Mg}$ crystal at $(2,4) 6$ and $(1,3) 293 \mathrm{~K}$, measured upon excitation by unfiltered X-ray radiation from a laboratory source. Fragments of the spectra in the visible region $(3,4)$ correspond to the spectra $(1,2)$ in an enlarged $(\times 10)$ scale.

(V), and secondly, the presence of thermally stimulated stages in the process of UV luminescence excitation.

Three relatively low-intensity partially overlapping photoluminescence bands at $2.0-2.1 \mathrm{eV}$ (I), $2.4-2.5 \mathrm{eV}$ (II), and 2.6-2.7 eV (III) are observed in the visible spectral region. Band II at $2.4-2.5 \mathrm{eV}$ dominates in this group in terms of intensity. The contribution of the band at $2.0-2.1 \mathrm{eV}$ is comparatively low. Bands I-III are located on the low-energy slope of the dominant UV band, so the parameters of the bands can be estimated only approximately. Luminescence in the visible region is lowtemperature; that is, the luminescence reaches its maximum intensity at low temperatures. At room temperature, the luminescence is almost completely quenched (Fig. 1).

In the energy range of $6.0-6.5 \mathrm{eV}$, the VUV band is observed at $6.25 \mathrm{eV}(\mathrm{VI})$. Luminescence is lowtemperature, because at room temperature, this band is almost completely quenched. Using a conventional spectroscopic recording system for the visible and UV spectral regions, the band at $6.25 \mathrm{eV}$ appears at the highenergy edge of the operating range of the recording system, and its characteristics cannot be determined reliably. For a more detailed study of this luminescence band, it is necessary to use the VUV recording system.

The VUV recording system has a lower operating limit of approximately $3.7 \mathrm{eV}$, which makes it possible to study the UV-VUV luminescence spectra of $\mathrm{BeO}: \mathrm{Mg}$ single crystals. However, due to technical limitations, the VUV recording system cannot be used to study photoluminescence in the visible spectral range; that is, the VUV system is not applicable to the study of the photoluminescence bands I-III.

The photoluminescence spectra of $\mathrm{BeO}$ and $\mathrm{BeO}: \mathrm{Mg}$ crystals, measured with the VUV recording system at 


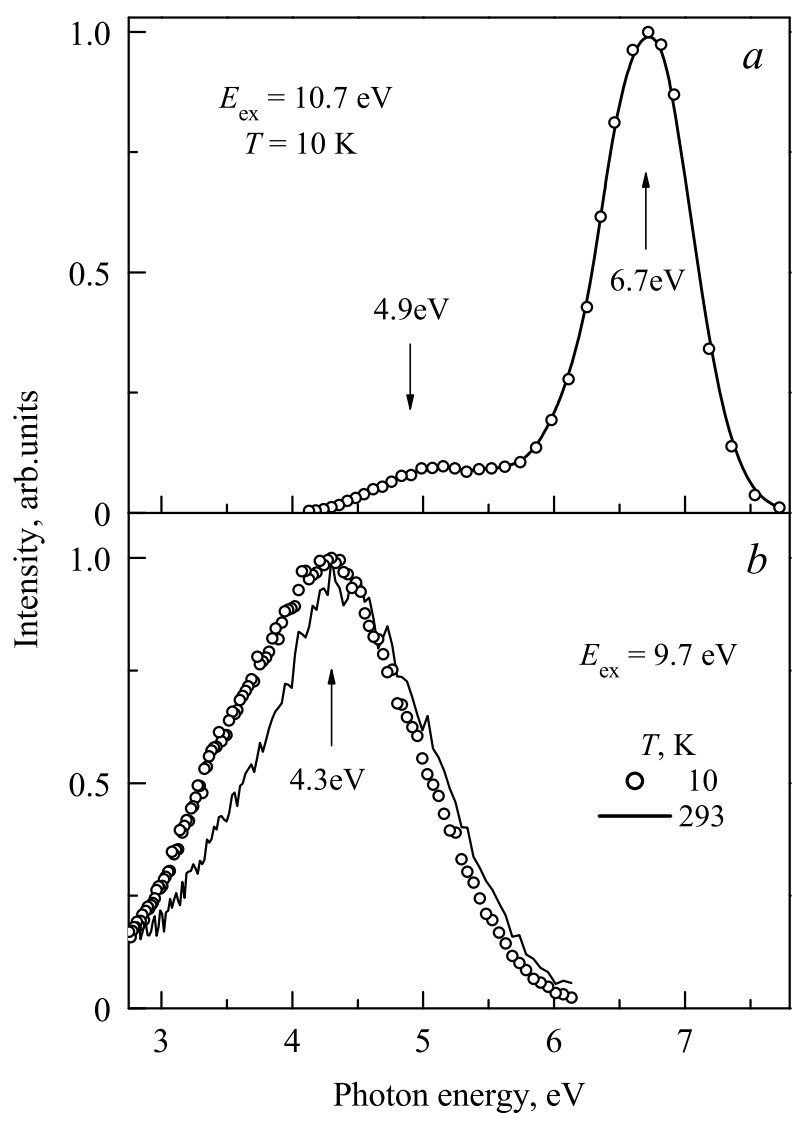

Figure 2. Photoluminescence spectra of (a) $\mathrm{BeO}$ and (b) BeO:Mg crystals, measured at $T=10$ and $293 \mathrm{~K}$, $E_{e x}=9.7$ and $10.7 \mathrm{eV}$.

excitation energy $E_{\text {ex }}=9.7$ and $10.7 \mathrm{eV}$, are shown in Fig. 2. The photoexcitation energies were selected on the basis of an analysis of the excitation and reflection spectra, which are discussed below.

The excitation energy of $E_{e x}=10.7 \mathrm{eV}$ corresponds to low-energy electron band-to-band transitions, that is, between the states of the top of the valence band and the bottom of the conduction band of $\mathrm{BeO}$. Under these conditions, self-luminescence bands at 4.9 and $6.7 \mathrm{eV}$ are effectively excited in all $\mathrm{BeO}$ and $\mathrm{BeO}: \mathrm{Mg}$ crystals. These bands can be observed most clearly in undoped BeO crystals at $T=10 \mathrm{~K}$ (Fig. $2 a$ ): the low-temperature VUV band at $6.7 \mathrm{eV}(\mathrm{FWHM}=0.81 \mathrm{eV})$ dominates in the photoluminescence spectrum, and the intensity of the UV band at $4.9 \mathrm{eV}$ reaches only $10 \%$ of the level of the dominant VUV band.

The excitation energy $E_{e x}=9.7 \mathrm{eV}$ is located below the energy thresholds of efficient photoexcitation of the intrinsic luminescence of $\mathrm{BeO}$ at 4.9 and $6.7 \mathrm{eV}[15$, 19]. Under these excitation conditions, the photoluminescence spectra of $\mathrm{BeO}: \mathrm{Mg}$ (Fig. 2b) are located in the region of $2.5-6 \mathrm{eV}$ and represent a wide complex band, the parameters of which depend on temperature. For example, with a temperature change from
10 to $293 \mathrm{~K}$, the position of the observed maximum varies from 4.3 to $4.4 \mathrm{eV}$, and the full width at the halfmaximum (FWHM) decreases from $1.75 \mathrm{eV}$ to $1.56 \mathrm{eV}$. This makes it possible to isolate the band at $4.3-4.4 \mathrm{eV}$ in the $\mathrm{BeO}: \mathrm{Mg}$ photoluminescence spectra, whereas a superposition of several partially overlapping bands is observed in the XRL spectra. We note two important experimental facts. First, the excitation at $E_{e x}=9.7 \mathrm{eV}$ of intense luminescence of $\mathrm{BeO}: \mathrm{Mg}$ unambiguously testifies that the photoluminescence band at $4.3-4.4 \mathrm{eV}$ is conditioned by the presence in this crystal of some defects that form the corresponding emission centers. Second, the observation of this photoluminescence band only in $\mathrm{BeO}$ crystals doped with a magnesium impurity gives grounds for discussing its possible connection with the presence of isovalent impurity magnesium ions in the $\mathrm{BeO}$ lattice.

Figure 3 shows fragments of low-temperature spectra of reflection and photoluminescence excitation at $6.7 \mathrm{eV}$ for an undoped $\mathrm{BeO}$ crystal and photoluminescence excitation spectra at $4.2 \mathrm{eV}$ for a $\mathrm{BeO}: \mathrm{Mg}$ crystal. Note that all the VUV spectra of photoluminescence excitation and the reflection spectra were recorded in the entire investigated energy range from 3.7 to $20 \mathrm{eV}$. However, only fragments of these spectra $(8.5-12.1 \mathrm{eV})$ are shown in Fig. 3 and discussed, where the manifestations of impurity states of $\mathrm{BeO}: \mathrm{Mg}$ were observed. All spectra are given in conventional units according to the $\mathrm{Y}$ scale.

A low-temperature $(T=10 \mathrm{~K})$ reflection spectrum of an undoped $\mathrm{BeO}$ crystal (Fig. 3a) was recorded simultaneously with the measurement of the excitation spectrum of the dominant low-temperature band of the intrinsic luminescence of $\mathrm{BeO}$ at $6.7 \mathrm{eV}$. These spectra were recorded under the same conditions as the $\mathrm{BeO}: \mathrm{Mg}$ spectra; they will be discussed in detail in Section 4 (Discussion of Results) in interpreting the excitation spectra of impurity luminescence in $\mathrm{BeO}: \mathrm{Mg}$. We note that all the VUV luminescence bands in $\mathrm{BeO}$ and $\mathrm{BeO}: \mathrm{Mg}$ crystals are low-temperature; they are not observed at room temperature.

Figure $3 b$ shows the photoluminescence excitation spectra of a $\mathrm{BeO}: \mathrm{Mg}$ crystal, measured at $T=10$ and $293 \mathrm{~K}$ by monitoring the luminescence at 6.0 and $4.3 \mathrm{eV}$ (for brevity, the spectra of PLE (6.0) and PLE (4.3)). The PLE (6.0) spectrum of the $\mathrm{BeO}: \mathrm{Mg}$ crystal at $T=10 \mathrm{~K}$ is located in the energy range of $E_{e x}>9.0 \mathrm{eV}$ (Fig. 3b). The low-energy slope of this spectrum (9.0$9.3 \mathrm{eV}$ ) has the form of a steeply rising curve, which reaches a maximum at $9.60 \mathrm{eV}$. On the high-energy slope of this spectrum, after a local minimum at $E_{0}$, a relatively narrow local maximum at $10.25 \mathrm{eV}$ is observed. In the energy region of approximately $10.5 \mathrm{eV}$, an absolute minimum of intensity is observed, after which there is a small monotonic increase in intensity and a saturation yield ( $8 \%$ of the maximum) at $E_{\text {ex }}>10.8 \mathrm{eV}$.

The PLE(4.3) spectrum of the $\mathrm{BeO}: \mathrm{Mg}$ crystal was 


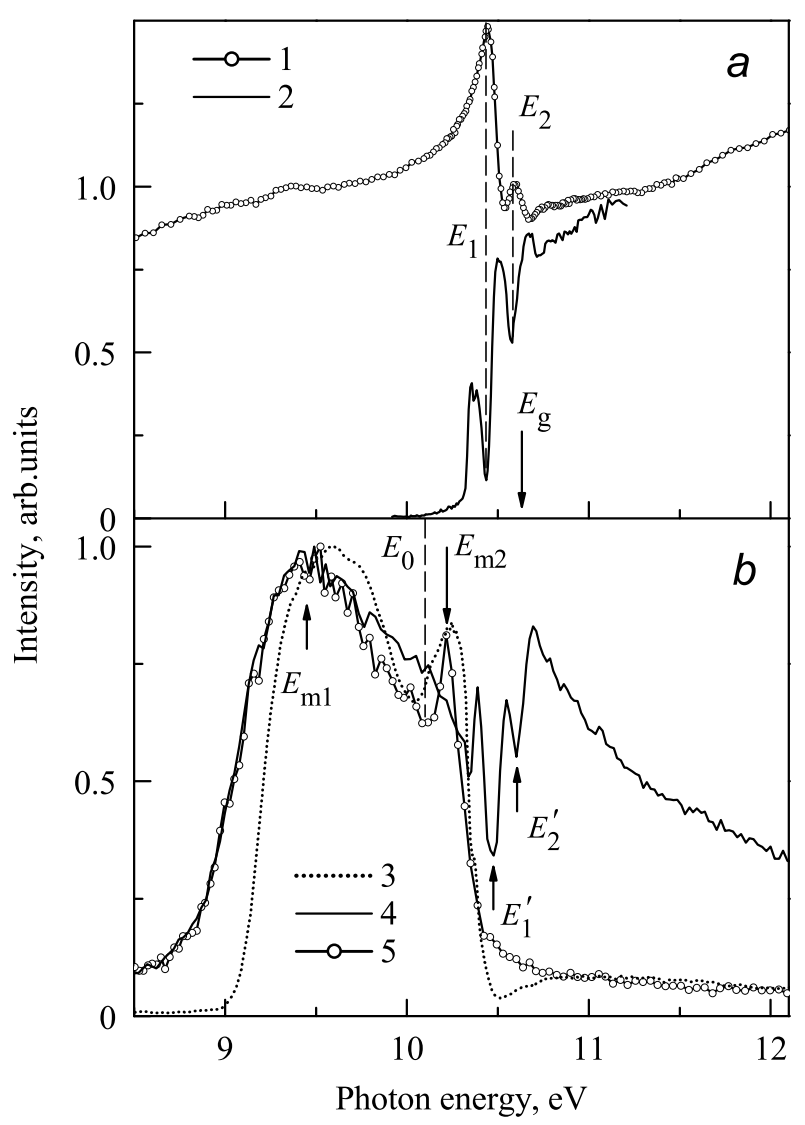

Figure 3. Fragments of (1) the reflection spectra and (2-5) E the photoluminescence excitation spectra of $(a)$ $\mathrm{BeO}$ and $(b) \mathrm{BeO}: \mathrm{Mg}$ crystals at $T=(1-4) 10$ and (5) $293 \mathrm{~K}$, measured by monitoring the luminescence at $E_{m}=(2) 6.7$, (3) 6.0, and $(4,5) 4.3 \mathrm{eV}$. All PLE spectra are normalized to unity at the intensity maximum; the reflection spectrum is shown in arbitrary units for better viewing. The arrow $\left(E_{g}\right)$ indicates the width of the band gap for a $\mathrm{BeO}$ crystal at $T=77 \mathrm{~K}$ by the data [12].

measured at $T=10$ and $293 \mathrm{~K}$, since the UV luminescence bands in $\mathrm{BeO}$ and $\mathrm{BeO}: \mathrm{Mg}$ are observed over a wide temperature range. At $T=293 \mathrm{~K}$, the PLE (4.3) spectrum of the $\mathrm{BeO}: \mathrm{Mg}$ crystal largely follows the PLE (6.0) spectrum (Fig. $3 b$ ). The arrows $E_{m 1}$ and $E_{m 2}$ correspond to the maxima of the PLE (4.3) spectrum. The principal difference lies in the broadening of the low-energy edge of the PLE (4.3) spectrum to the transparency region of the $\mathrm{BeO}$ crystal: the efficient excitation of the UV band of BeO:Mg begins at $E_{e x}>8.5 \mathrm{eV}$ (Fig. 3b). This indirectly indicates the formation of shallow impurity states in $\mathrm{BeO}: \mathrm{Mg}$, which cause absorption bands near (below) the fundamental absorption edge of $\mathrm{BeO}$.

At $T=10 \mathrm{~K}$, the low-energy $(8.5-10 \mathrm{eV})$ part of the PLE (4.3) spectrum is practically identical in shape to the spectrum for room temperature. However, the high-energy part $\left(E_{e x}>10 \mathrm{eV}\right)$ of the low-temperature PLE (4.3) spectrum is fundamentally different in shape (Fig. $3 b$ ): first, the maximum $E_{m 2}$ is shifted by $0.17 \mathrm{eV}$ to the high-energy region and at low temperature is observed at $10.39 \mathrm{eV}$; second, the UV luminescence band is efficient ( $85 \%$ of the maximum) excited both in the exciton region and in the region of creation of separated electrons and holes. The narrow dips and in the low-temperature PLE (4.3) spectrum (Fig. 3b) are comparable with the features of $\mathrm{E}_{1}^{\prime}$ and $\mathrm{E}_{2}^{\prime}$ in the reflection spectra and the low-temperature photoluminescence excitation spectra at $6.7 \mathrm{eV}$ (Fig. 3a). The fact of the effective excitation of the UV band of the $\mathrm{BeO}: \mathrm{Mg}$ luminescence in the region of the band-to-band transitions gives grounds for discussing the possibility of manifesting this band in recombination processes.

\subsection{Temperature Dependence of Luminescence}

The XRL spectra of a BeO:Mg crystal, measured at fixed temperatures in the range of 6 to $300 \mathrm{~K}$, are presented in Fig. 4. The study of the temperature dependences of the luminescence intensities of the steady-state XRL bands is complicated by the fact that relatively low-intensity bands of the visible (I-III) and VUV (VI) ranges are located on the slopes of the dominant bands (IV and V) of UV luminescence. Therefore, the analysis of the curves for the temperature dependence (TQ) of the luminescence intensity is preceded by considering the change in the shape of the spectra with a temperature change from 8 to $300 \mathrm{~K}$. In the visible region of the spectrum the luminescence band (I) does not exhibit a noticeable temperature dependence, while the (II) and (III) bands, while retaining the shape,

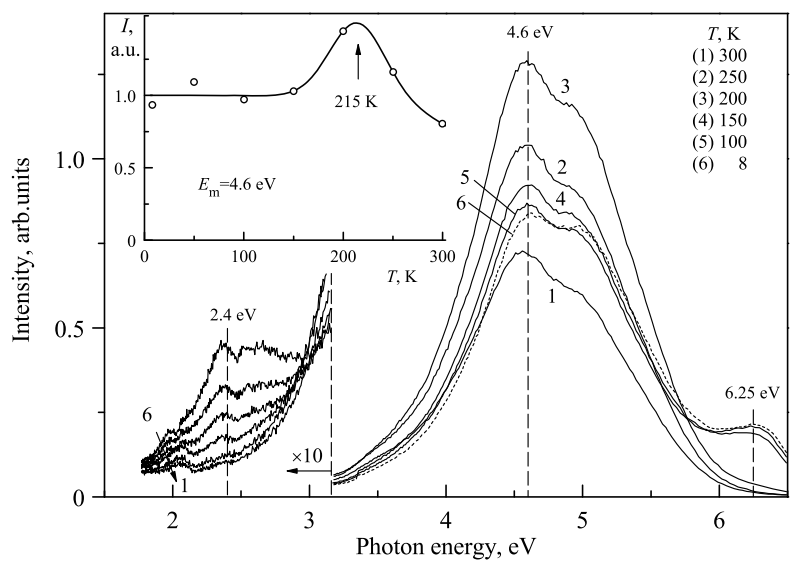

Figure 4. The XRL spectra of a BeO:Mg crystal, measured at fixed temperatures in the range of 6 to $300 \mathrm{~K}$. Fragments of the spectra in the visible region (1-6) correspond to the spectra (1-6) in an enlarged $(\times 10)$ scale. Inset: temperature dependence of the $\mathrm{XRL}$ intensity at $4.6 \mathrm{eV}$. 
decay slowly and uniformly in intensity to a level corresponding to the intensity of the long-wavelength slope of the dominant UV band at $T=300 \mathrm{~K}$ (Fig. 4). In the VUV spectral region, the band (VI) also decays in intensity, retaining the shape, but the intensity decay occurs unevenly in temperature: at $T=8-150 \mathrm{~K}$, only a slight decrease in intensity occurs; at $T=150-200 \mathrm{~K}$, the XRL intensity decreases sharply; and at $T=200-300 \mathrm{~K}$, the XRL intensity decreases only in small limits to a level corresponding to the intensity of the short-wavelength slope of the dominant UV bands at $T=300 \mathrm{~K}$.

The dominant partially overlapping UV bands (IV) and $(\mathrm{V})$ retain their shape with a temperature change from 8 to $300 \mathrm{~K}$, but vary in intensity nonmonotonically (Fig. 5). The inset to Fig. 5 shows the curve of the temperature dependence of the XRL intensity measured by monitoring the luminescence at $4.6 \mathrm{eV}$ (further, TQ $(4.6 \mathrm{eV})$ ): stable intensity at $T=8-150 \mathrm{~K}$; an increase in intensity by one and a half ('building-up') at $T=150$ $215 \mathrm{~K}$; and gradual decrease to the level $3 / 4$ of the original at $T=215-300 \mathrm{~K}$. It is not possible to separate the contributions of the bands (IV) and (V) into the recorded TQ $(4.6 \mathrm{eV})$ curve, but it is obvious that the temperature quenching of both bands will occur at temperatures a lot above room temperature.

Figure 5 demonstrates the temperature dependence curves of the steady-state XRL intensity, measured in the bands at 6.25 and $2.4 \mathrm{eV}$, denominated as TQ $(6.25 \mathrm{eV})$ and TQ $(2.4 \mathrm{eV})$. The temperature dependence TQ $(6.25 \mathrm{eV})$ in the region of $T>150 \mathrm{~K}$ is approximated by Eq. (1), the mathematical expression of which formally corresponds to the well-known Mott law for the temperature quenching of luminescence,

$$
I(T)=I_{\mathrm{m}}\left[1+\omega \exp \left(-E / k_{\mathrm{B}} T\right)\right]^{-1},
$$

where $I_{m}$ is the maximum value of the intensity of the low-temperature steady-state XRL (arb. units), $\omega$ is the dimensionless preexponential factor, $E$ is the activation energy of the temperature quenching $(\mathrm{eV}), k_{B}$ is the Boltzmann constant $(\mathrm{eV} / \mathrm{K})$, and $T$ is temperature $(\mathrm{K})$. We denote the characteristic temperature of the temperature quenching process by $T_{1 / 2}$, for which $I\left(T_{1 / 2}\right)=I_{\mathrm{m}} / 2$. It can be seen from Eq. (1) that

$$
T_{1 / 2}=\frac{E}{k_{\mathrm{B}} \ln (\omega)} .
$$

Taking into account Eq. (2), Eq. (1) can be represented as follows:

$$
I(T)=I_{\mathrm{m}}\left[1+\exp \left(-\frac{E}{k_{\mathrm{B}} T}\left(1-\frac{T}{T_{1 / 2}}\right)\right)\right]^{-1} .
$$

The temperature dependence TQ $(2.4 \mathrm{eV})$ in a wide temperature range $(6-300 \mathrm{~K})$ is approximated by Eq. (4), the mathematical expression of which formally corresponds to the known Street law for the temperature quenching

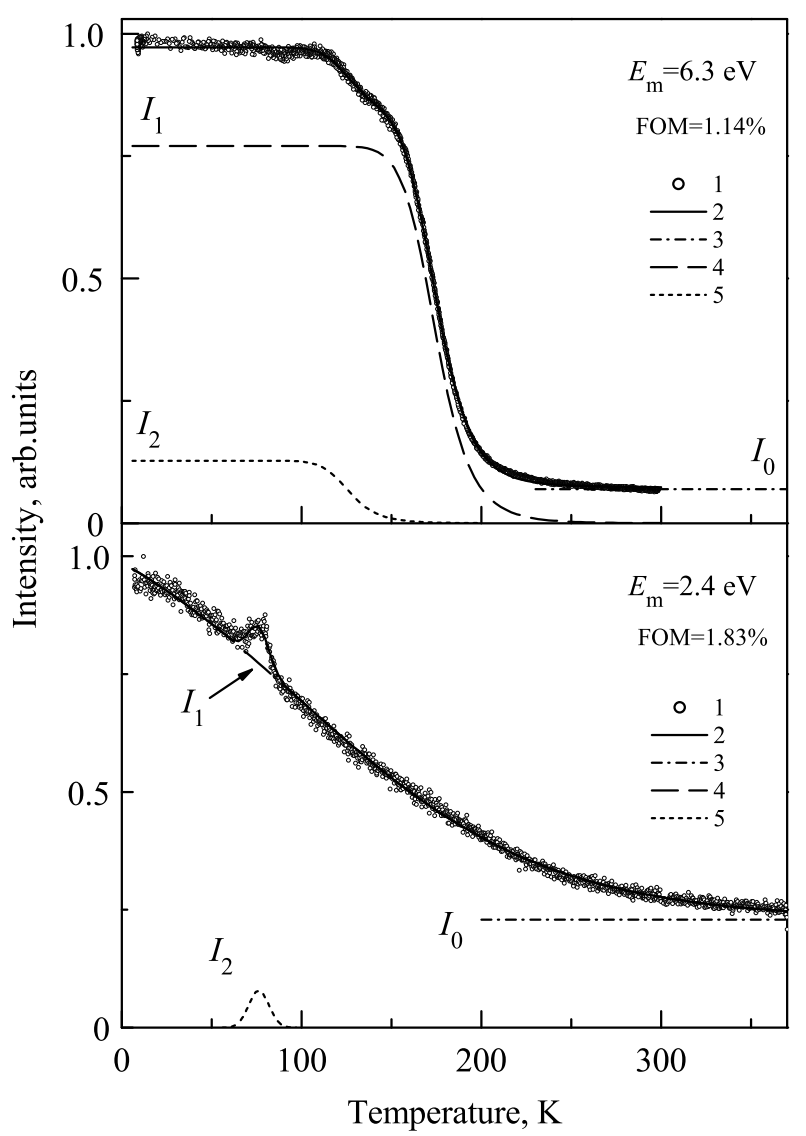

Figure 5. (1) Temperature dependences of the stationary XRL intensity, measured in the bands at 6.25 and $2.4 \mathrm{eV}$; (2) calculated curve $I(T)$ for

approximation; and the elementary components of the approximation curve (3) $I_{0},(4), I_{1}(\mathrm{~T})$, and (5), $I_{2}(T)$.

of luminescence, namely,

$$
I(T)=I_{\mathrm{m}}\left[1+\omega \exp \left(T / T_{0}\right)\right]^{-1},
$$

where $I_{m}$ is the maximum value of the intensity of the low-temperature steady-state XRL (arb. units), $\omega$ is the dimensionless preexponential factor, $T_{0}$ is a constant $(\mathrm{K})$, and $T$ is temperature $(\mathrm{K})$. We denote the characteristic temperature of the temperature quenching process by $T_{1 / 2}$, for which $I\left(T_{1 / 2}\right)=I_{m} / 2$. We can obtain from Eq. (4) that

$$
T_{1 / 2}=-T_{0} \ln (\omega) .
$$

Taking into account Eq. (5), Eq. (4) can be written in a rationalized form, convenient for numerical analysis of the experimental data, that is,

$$
I(T)=I_{\mathrm{m}}\left[1+\exp \left(\frac{T}{T_{0}}\left(1-T_{1 / 2} / T\right)\right)\right]^{-1} .
$$

The temperature dependences TQ $(6.25 \mathrm{eV})$ and TQ $(2.40 \mathrm{eV})$ for the entire temperature range studied (6- 
$300 \mathrm{~K})$ were approximated by the sum of three components:

$$
I(T)=I_{0}+I_{1}(T)+I_{2}(T),
$$

where $I_{0}$ is a constant, the level of a constant temperature-independent background; $I_{1}(T)$ is the main process describing the temperature quenching of steadystate XRL, which is given by Eq. (3) for TD $(6.25 \mathrm{eV})$ and Eq. (6) for TQ $(2.40 \mathrm{eV})$; and $I_{2}(T)$ is an additional term introduced for mathematical reasons to improve the convergence of the results in a limited temperature range, which is given by Eq. (3) for TQ $(6.25 \mathrm{eV})$ and the Gaussian function (Eq. (8)) for TQ $(2.40 \mathrm{eV})$

$$
I_{2}(T)=I_{\mathrm{m}} \exp \left(-\left(\frac{T-T_{0}}{D}\right)^{2}\right),
$$

where the parameters of the Gaussian function are the following: $I_{m}$ is the amplitude, $T 0$ is the temperature position of the maximum, and $D=\mathrm{FWHM} / \sqrt{2 \ln 2}$.

The quality of the approximation was evaluated using the figure of merit (FOM) criterion

$$
\mathrm{FOM}=\frac{\sum_{k}\left|I\left(T_{k}\right)-I_{k}\right|}{\sum_{k} I_{k}} \times 100 \%,
$$

where $I_{k}$ are the experimental values of the steady-state XRL intensity, measured at the temperature points $T_{k}$, and $I\left(T_{k}\right)$ are the values of the approximating curve at the temperature points $T_{k}$. The parameters of the best approximation (Table 1) were obtained at $\mathrm{FOM}=1.14 \%$ for TQ $(6.25 \mathrm{eV})$ and $1.83 \%$ for TQ $(2.40 \mathrm{eV})$.

\begin{tabular}{|c|c|c|c|}
\hline \multirow{2}{*}{ Parameter } & \multicolumn{3}{|c|}{ Process } \\
\hline & $I_{0}$ & $I_{1}(T)$ & $I_{2}(T)$ \\
\hline \multicolumn{4}{|c|}{$E_{\mathrm{m}}=6.25 \mathrm{eV} \quad(\mathrm{FOM}=1.14 \%)$} \\
\hline Formula & $I_{0}=I \mathrm{~m}$ & (3) & (3) \\
\hline$I_{m}$ & 0.074 & 0.771 & 0.128 \\
\hline$E, \mathrm{eV}$ & - & 0.273 & 0.173 \\
\hline $\ln \omega$ & - & 18.161 & 15.861 \\
\hline$T_{1 / 2}, \mathrm{~K}$ & - & 174.7 & 126.6 \\
\hline \multicolumn{4}{|c|}{$E_{\mathrm{m}}=2.40 \mathrm{eV} \quad(\mathrm{FOM}=1.83 \%)$} \\
\hline Formula & $I_{0}=I \mathrm{~m}$ & (6) & (8) \\
\hline$I_{m}$ & 0.230 & 0.939 & 0.079 \\
\hline$-\ln \omega$ & - & 1.423 & - \\
\hline$T_{1 / 2}, \mathrm{~K}$ & - & 98.03 & - \\
\hline$T_{0}, \mathrm{~K}$ & - & 68.90 & 76.18 \\
\hline FWHM, K & - & - & 13.1 \\
\hline
\end{tabular}

Table 1. Parameters of the best approximation for TQ $\left(E_{m}\right)$

I0 is a constant level of the temperatureindependent background.

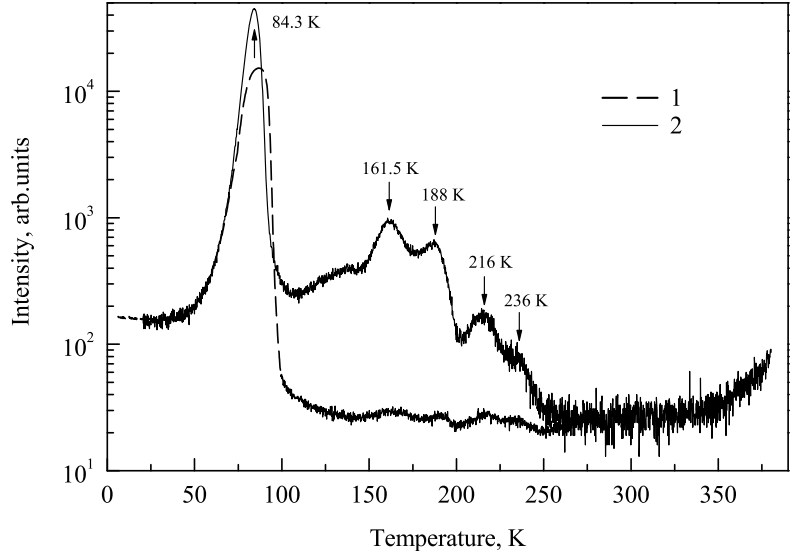

Figure 6. Overview curves of the thermally stimulated luminescence of (1) $\mathrm{BeO}$ and (2) $\mathrm{BeO}: \mathrm{Mg}$ crystals, measured at a linear heating rate of $0.1 \mathrm{~K} / \mathrm{s}$ after preliminary X-ray irradiation at $T_{0}=6 \mathrm{~K}$.

\subsection{Low-Temperature $T L$}

Figure 6 shows an overview curve of the lowtemperature $\mathrm{TL}$ of a $\mathrm{BeO}: \mathrm{Mg}$ crystal, recorded in the spectral-integral mode $(1.2-6.2 \mathrm{eV})$ at a linear heating rate of $0.1 \mathrm{~K} / \mathrm{s}$ after preliminary X-ray irradiation at $T_{0}=6 \mathrm{~K}$. We note two important circumstances. First, a sensitive recording system was used in the measurement, enabling the recording of the TL glow curves in a dynamic range up to six decimal orders of intensity change. Therefore, the overview curves are presented in a semi-logarithmic (along the ordinate axis) scale, which ensures observing not only dominant but also low-intensity peaks. Second, the TL of undoped $\mathrm{BeO}$ crystals was previously studied in [40, 41], where the first order of kinetics and the activation energy of $E=0.11 \mathrm{eV}$ were determined for a low-temperature peak at $84-85.1 \mathrm{~K}$. In our work, the TL glow curve of undoped $\mathrm{BeO}$ was reproduced under the same conditions, at which the TL of BeO:Mg crystals was studied. The TL glow curve for undoped $\mathrm{BeO}$ is given in Fig. 6 only for comparison: it was measured under the same conditions, in which the TL for $\mathrm{BeO}: \mathrm{Mg}$ was recorded, and then arbitrarily normalized for intensity for better viewing when compared with the $\mathrm{BeO}: \mathrm{Mg}$ TL glow curve.

The peak in the temperature range of $84-86 \mathrm{~K}$ dominates in both TL glow curves (BeO and $\mathrm{BeO}: \mathrm{Mg})$. In the transition from $\mathrm{BeO}$ to $\mathrm{BeO}: \mathrm{Mg}$, the position of the maximum $\left(T_{m}\right)$ of this peak varies insignificantly: from $85.1 \mathrm{~K}(\mathrm{BeO})$ to $84.3 \mathrm{~K}(\mathrm{BeO}: \mathrm{Mg})$; therefore, for brevity, it is conditionally designated as 'a TL peak at $85 \mathrm{~K}$ '. However, the shape of this TL peak changes significantly in transition to $\mathrm{BeO}: \mathrm{Mg}$ : the amplitude increases by two to three times; the full width at the halfmaximum $(\Delta)$ decreases from $12.6 \mathrm{~K}(\mathrm{BeO})$ to $7.86 \mathrm{~K}$ (BeO:Mg). 
The thermally activated parameters of the dominant TL peak at $85 \mathrm{~K}$ for $\mathrm{BeO}$ and $\mathrm{BeO}: \mathrm{Mg}$ crystals were calculated using the peak shape analysis. Assuming the considered TL peak to be elementary, within the framework of this analysis, the peak asymmetry parameter (form factor) $\mu_{g}=\delta / \Delta$, where $\delta$ is the high-temperature half-width at the half-maximum of the TL peak, is determined. In our measurements, $\mu_{g} \approx 0.42$ was obtained for both crystals, which corresponds to the first order kinetics [42]. For this case, the activation energy $E$ can be determined by the equation $[43,44]$

$$
E=2.52 k_{\mathrm{B}} T_{\mathrm{m}}^{2} / \Delta-2 k_{\mathrm{B}} T_{\mathrm{m}} .
$$

The thermal activation parameters of the dominant TL peak, determined by Eq. (10), are presented in Table 2 in comparison with the analogous data for $\mathrm{BeO}: \mathrm{Zn}$ [32]. It follows from Table 2 that doping of beryllium oxide with isovalent impurities ( $\mathrm{Zn}$ and $\mathrm{Mg}$ ) leads to a qualitatively identical change in the parameters of the TL peak at $85 \mathrm{~K}$ : a decrease in the full width at the peak half-maximum $(\Delta)$ and an increase in the activation energy $(E)$. In addition, we note that the narrowing of the TL peak in all the considered cases is accompanied by a corresponding increase in its amplitude. However, the quantitative changes are different, and for both parameters $(\Delta$ and $E)$, there is a tendency of $\mathrm{BeO}-\mathrm{BeO}: \mathrm{Mg}$ - BeO:Zn. In other words, the quantitative changes of these parameters in $\mathrm{BeO}: \mathrm{Mg}$ crystals are somewhat smaller than those observed for the BeO:Zn crystal.

Table 2. Parameters of the TL peak at $85 \mathrm{~K}$ in $\mathrm{BeO}, \mathrm{BeO}: \mathrm{Mg}$, and $\mathrm{BeO}: \mathrm{Zn}$

\begin{tabular}{lccc}
\hline \multirow{2}{*}{ Crystal } & \multicolumn{3}{c}{ Parameter } \\
\cline { 2 - 4 } & $T_{\mathrm{m}}, \mathrm{K}$ & $\Delta, \mathrm{K}$ & $E, \mathrm{eV}$ \\
\hline $\mathrm{BeO}$ & 85.1 & 12.6 & 0.11 \\
$\mathrm{BeO}: \mathrm{Mg}$ & 84.3 & 7.86 & 0.18 \\
$\mathrm{BeO}: \mathrm{Zn}$ & 85.6 & 7.3 & 0.20 \\
\hline
\end{tabular}

The parameters for $\mathrm{BeO}: \mathrm{Zn}$ are taken from [32]..

Four relatively low-intensity TL peaks at $161.5,188$, 216 , and $236 \mathrm{~K}$ are observed for both $\mathrm{BeO}$ and $\mathrm{BeO}: \mathrm{Mg}$; however, in the transition to $\mathrm{BeO}: \mathrm{Mg}$, the intensity of these peaks increases several times: $\times 3(236 \mathrm{~K}), \times 5.9$ $(216 \mathrm{~K}), \times 24(188 \mathrm{~K})$, and $\times 32.5(161.5 \mathrm{~K})$. All four low-intensity peaks of TL are partially overlapping and less suitable for determining their thermal activation parameters.

A characteristic feature of the experimental data for $\mathrm{BeO}: \mathrm{Mg}$ (Fig. 6) is the presence of an appreciable background level of luminescence, the intensity of which varies little in the temperature range of $6-150 \mathrm{~K}$, decreases approximately twice in the temperature range of $150-250 \mathrm{~K}$, and decreases by more than an order of magnitude at temperatures above $250 \mathrm{~K}$ (Fig. 6).

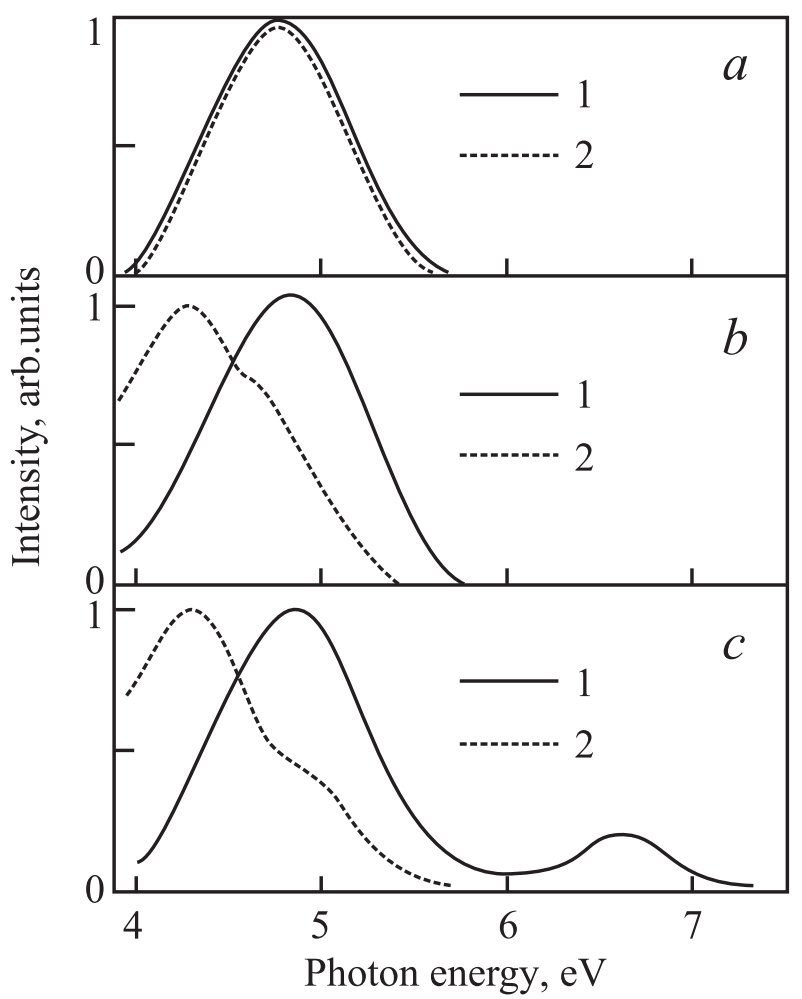

Figure 7. Normalized TL spectra for beryllium oxide crystals: (1) $\mathrm{BeO}$ and (2) $\mathrm{BeO}: \mathrm{Mg}$, recorded at (a) 520, (b) 300 , and (c) $100 \mathrm{~K}$.

The TL spectra of an undoped $\mathrm{BeO}$ crystal and a $\mathrm{BeO}: \mathrm{Mg}$ crystal are presented in Fig. 7. It is seen from the figure that the spectral composition of the TL of $\mathrm{BeO}$ is mainly located in the $\mathrm{BeO} \mathrm{UV}$ band at $4.9 \mathrm{eV}$, which coincides with that for the intrinsic luminescence of beryllium oxide under steady-state excitation. It should be noted that, at temperatures below $150 \mathrm{~K}$, a relatively low-intensity band of $6.7 \mathrm{eV}$ is present in the TL spectra of $\mathrm{BeO}$, suggesting a certain probability of the formation of a self-localized exciton, which determines the band of intrinsic luminescence at $6.7 \mathrm{eV}$, in recombination processes. The same is typical for the $\mathrm{BeO}: \mathrm{Mg}$ TL spectrum. However, at lower temperatures, the luminescence band at $4.3 \mathrm{eV}$ dominates in the TL spectrum, due to the presence of impurity magnesium ions in the $\mathrm{BeO}$ lattice.

\section{DISCUSSION OF RESULTS}

Low-Energy Electronic Excitation and Luminescence. The optical spectra of undoped $\mathrm{BeO}$ single crystals are studied in detail earlier (see, for example, references to papers mentioned in the Introduction) and can be used as reference data for analyzing the experimental results obtained for doped $\mathrm{BeO}$ crystals. It should be noted that in the investigated energy range $(3.7-20 \mathrm{eV})$ 
the low-temperature $(T=10 \mathrm{~K})$ reflection spectra of undoped $\mathrm{BeO}$ crystals and $\mathrm{BeO}: \mathrm{Mg}$ crystals are practically identical in structure. However, the reflection spectra of the best quality were obtained for undoped $\mathrm{BeO}$ crystals with a natural growth face. A fragment of such a spectrum recorded at $T=10 \mathrm{~K}$ is shown in Fig. 3. The lowest-energy reflection peaks, corresponding to energies $E_{1}$ and $E_{2}$ (Fig. 3), are comparable in energy position to the exciton absorption maxima of $E_{n=1}$ and $E_{n=2}$ previously recorded for an undoped $\mathrm{BeO}$ crystal [14].

Upon excitation above the energy threshold for the creation of free excitons in $\mathrm{BeO}(10 \mathrm{eV}[15,19])$ or band-to-band excitation $\left(E_{g}=10.63 \mathrm{eV}\right.$ at $T=77 \mathrm{~K}$ [14]), both bands of intrinsic luminescence (4.9 and $6.7 \mathrm{eV}$ ), characteristic of undoped $\mathrm{BeO}$, appear in the $\mathrm{BeO}: \mathrm{Mg}$ luminescence spectrum at $T=10 \mathrm{~K}$. These bands if intrinsic luminescence of $\mathrm{BeO}$, caused by radiative annihilation of self-trapped excitons of two types, have been repeatedly discussed earlier for undoped $\mathrm{BeO}$ $[15,19], \mathrm{BeO}$ with heterovalent impurities [45], and $\mathrm{BeO}: \mathrm{Zn}$ [32]. Along with them, three groups of bands are observed in the low-temperature luminescence spectrum of $\mathrm{BeO}: \mathrm{Mg}$, which are not characteristic of undoped $\mathrm{BeO}$ crystals or $\mathrm{BeO}$ crystals with heterovalent impurities, nor are they intrinsic defects of the $\mathrm{BeO}$ lattice.

The VUV luminescence band $(6.0-6.25 \mathrm{eV})$ is observed only in $\mathrm{BeO}$ with isovalent impurities: the band at $6.25 \mathrm{eV}$ (VI) in $\mathrm{BeO}: \mathrm{Mg}$ crystals (Fig. 1) and the band at $6.0 \mathrm{eV}$ in $\mathrm{BeO}: \mathrm{Zn}$ crystals [32]. It does not occur in undoped $\mathrm{BeO}$ crystals, $\mathrm{BeO}$ crystals with heterovalent impurities or color centers. The PLE spectrum at $6.25 \mathrm{eV}$ in $\mathrm{BeO}: \mathrm{Mg}$ is similar in its properties to the PLE spectrum of the band at $6.0 \mathrm{eV}$ in $\mathrm{BeO}: \mathrm{Zn}$ crystals [32]: it has a clearly pronounced low-energy threshold corresponding to the long-wavelength fundamental absorption edge of the crystal; an increase in the energy of exciting photons above this excitation threshold leads to a sharp increase in the luminescence intensity at $6.25 \mathrm{eV}$; it is concentrated in the region of fundamental absorption below the first exciton maximum of beryllium oxide, that is, in the energy range from 9.0 to $10.4 \mathrm{eV}$.

The UV luminescence band at $4.3-4.4 \mathrm{eV}$ (IV) was detected only in $\mathrm{BeO}: \mathrm{Mg}$ crystals (Figs. 1 and 2). Although many of its properties are similar to those for the VUV band at $6.25 \mathrm{eV}$, the UV band at $4.3 \mathrm{eV}$ in $\mathrm{BeO}: \mathrm{Mg}$ is fundamentally different.

Our measurements of UV luminescence at $4.3 \mathrm{eV}$ in $\mathrm{BeO}: \mathrm{Mg}$ were performed for the temperature range of $6-300 \mathrm{~K}$, but it is obvious that this luminescence should be observed outside the studied temperatures over a wider temperature range.

In the entire investigated temperature region of 5$300 \mathrm{~K}$, the low-energy edge of the PLE (4.3) spectrum is broadened to the transparency region of the $\mathrm{BeO}$ crystal so that the efficient excitation of the UV band of
BeO:Mg begins at $E_{e x}>8.5 \mathrm{eV}$ (Fig. $4 b$ ). This indirectly indicates the formation of shallow impurity states in $\mathrm{BeO}: \mathrm{Mg}$, which cause absorption bands near (below) the fundamental absorption edge of $\mathrm{BeO}$.

Maximum $E_{m 2}$ in the PLE $(4.3 \mathrm{eV})$ spectrum is narrower and more acute; it is shifted to the high-energy region by $0.03 \mathrm{eV}$ at room temperature and by $0.17 \mathrm{eV}$ at $10 \mathrm{~K}$.

At $T=10 \mathrm{~K}$, the UV luminescence band is efficiently ( $85 \%$ of the maximum) excited in the exciton region and in the region of creation of separated electrons and holes. The narrow dips and in the low-temperature PLE $(4.3 \mathrm{eV})$ spectrum (Fig. $3 b)$ are comparable with the features of $E_{1}$ and $E_{2}$ in the reflection spectra and the low-temperature photoluminescence excitation spectra at $6.7 \mathrm{eV}$ (Fig. 3a). The fact of the efficient excitation of the UV band of the $\mathrm{BeO}: \mathrm{Mg}$ luminescence in the region of the band-to-band transitions gives grounds for discussing the possibility of manifesting this band in recombination processes.

The profile of the excitation spectrum in the region of 9.0-10.4 eV (Fig. 3b) corresponds to the exciton mechanism of photoluminescence excitation, which involves the participation of free excitons in the process of transfer of electron excitation energy from the host to isovalent impurity centers. A comparison of the profiles of the low-temperature spectra of PLE $(4.3 \mathrm{eV})$ and PLE $(6.7 \mathrm{eV})$ (Fig. 4) gives grounds for discussing the transfer of the energy of electronic excitations from the host to impurity magnesium ions by migration of free excitons. Here we are talking about impurity magnesium ions occupying regular positions in the $\mathrm{BeO}$ crystal lattice, in the vicinity of which the radiative relaxation of electronic excitations occurs. The generality of the spectral-luminescent properties of the band at 6.0 $6.25 \mathrm{eV}$ in $\mathrm{BeO}$ crystals doped with isovalent impurities enable us to speak about the general nature of this luminescence in $\mathrm{BeO}: \mathrm{Mg}$ and $\mathrm{BeO}: \mathrm{Zn}$ crystals: the luminescence band at $6.0 \mathrm{eV}$ in $\mathrm{BeO}: \mathrm{Zn}$ was previously interpreted as the luminescence of relaxed exciton-like states near the isovalent impurity [32]. It is interesting to note that in a 'mirror' $\mathrm{MgO}: \mathrm{Be}$ system, luminescent centers associated with the beryllium impurity were found $\left(\mathrm{E}_{m} \approx 6.2 \mathrm{eV}\right.$ [34]), the characteristics of which are very close to those for the luminescence band at $6.25 \mathrm{eV}$ in $\mathrm{BeO}: \mathrm{Mg}$.

On the basis of the data presented, the profile of the excitation spectrum of the impurity UV and VUV luminescence of $\mathrm{BeO}: \mathrm{Mg}$ crystals in the region of the lowenergy fundamental absorption edge (Fig. $3 b$ ) can be confidently interpreted. The low-energy slope of both PLE $(4.3 \mathrm{eV})$ and PLE $(6.0 \mathrm{eV})$ bands is due mainly to an increase in the fundamental absorption of the crystal above $9.0 \mathrm{eV}$. However, with a further increase in the energy of the exciting photons, the absorption coefficient increases, which ultimately leads to a decrease in the thickness of the region of the crystal where excitation of nonexcited excitons occurs. At $E_{m 1}=9.45 \mathrm{eV}$, 
the maximum in the luminescence excitation spectrum takes place (Fig. 3b). When the thickness of this region becomes commensurable with the mean free path of excitons, there is an increase in nonradiative energy loss on the surface of the crystal. This determines the highenergy slope of the excitation band at an energy above $E_{m 1}=9.45 \mathrm{eV}$. At $E_{0}=10.1 \mathrm{eV}$, a minimum is observed in the luminescence excitation spectrum. The broadening of the low-energy edge of the PLE $(4.3 \mathrm{eV})$ spectrum to the transparency region of the crystal should be attributed to the formation of shallow impurity states in $\mathrm{BeO}: \mathrm{Mg}$, which cause absorption bands near (below) the fundamental absorption edge.

The origin of the second maximum $\left(E_{m 2}=10.22 \mathrm{eV}\right.$, Fig. $3 b$ ) in the PLE spectrum at 4.2 and $6.0 \mathrm{eV}$ is due to a different cause. The experimental results for $\mathrm{BeO}: \mathrm{Mg}$ in combination with the known literature data for $\mathrm{BeO}$ make it possible to discuss, as the most probable, two reasons: the instrumental one and the excitation of nonrelaxed excitons bound to a magnesium impurity.

\section{The First Reason}

It is known [19] that the intrinsic luminescence at $6.7 \mathrm{eV}$ in a $\mathrm{BeO}$ crystal is due to the radiative annihilation of self-trapped excitons, the main channel for the creation of which is the self-trapping of free excitons. The band at $6.7 \mathrm{eV}$ is excited in the region of fundamental absorption of $\mathrm{BeO}$, but with a lower efficiency in the exciton absorption band compared with the region corresponding to the band-to-band transitions; that is, in the region of $10-10.6 \mathrm{eV}$, the excitation spectrum of the PL band at $6.7 \mathrm{eV}$ is a monotonically increasing curve (Fig. 3). It is the increase in the intensity of broadband luminescence at $6.7 \mathrm{eV}$ at $E_{e x}>10 \mathrm{eV}$ that, in our opinion, causes the appearance of an additional maximum at $E_{e x}=10.25 \mathrm{eV}$ in the photoluminescence excitation spectrum recorded by monitoring the luminescence at 4.2 and $6.0 \mathrm{eV}$ (Fig. 3b). Indeed, the $\mathrm{BeO}: \mathrm{Mg}$ luminescence spectrum in the energy range of $3.0-6.0 \mathrm{eV}$ is a superposition of several partially overlapping bands: the $\mathrm{BeO}$ intrinsic luminescence bands at 4.9 and $6.7 \mathrm{eV}$ and the luminescence bands at 4.3-4.4 and 6.0-6.25 eV due to the isovalent impurity in the BeO lattice (Figs. 1 and 2). The experimental excitation spectrum recorded by monitoring the luminescence at $6.0 \mathrm{eV}$ (Fig. $3 b$ ) is a superposition of the excitation spectra of the photoluminescence bands at 6.0 and $6.7 \mathrm{eV}$. In addition, it is known [19] that a close connection exists between the bands of the intrinsic luminescence of $\mathrm{BeO}$, due to their common nature: excitation of the dominant band at $6.7 \mathrm{eV}$ also leads to excitation of the band at $4.9 \mathrm{eV}$. In turn, the band of intrinsic luminescence at $4.9 \mathrm{eV}$ is characterized by a significant overlap with an impurity band at $4.3-4.3 \mathrm{eV}$, so that the experimental excitation spectrum recorded by monitoring the luminescence at $4.2 \mathrm{eV}$ in $\mathrm{BeO}: \mathrm{Mg}$ crystals is a superposition of the excitation spectra of photoluminescence bands at 4.2 and $4.9 \mathrm{eV}$.

\section{The Second Reason}

If the excitation energy exceeds a certain threshold value $E_{t r}$, then excitation of nonrelaxed near-impurity excitons, that is, nonrelaxed excitons associated with an impurity of magnesium, is possible. The transfer of the energy of electronic excitations by migration of free excitons with energy $E_{e x}>E_{t r}$ makes the main contribution to this excitation mechanism, because direct creation of near-impurity excitons is unlikely due to a low impurity concentration. Excitation of a near-impurity exciton can be considered as a probable cause of the appearance of the second maximum of $E_{m 2}=10.39 \mathrm{eV}$ in the low-temperature PLE $(4.3 \mathrm{eV})$ spectrum of the $\mathrm{BeO}: \mathrm{Mg}$ crystal. The probable energy threshold of $E_{t r}=10.21-10.45 \mathrm{eV}$ of photoexcitation of a near-impurity exciton in $\mathrm{BeO}$ crystals was previously predicted [25]. The value of $E_{m 2}=10.39 \mathrm{eV}$ obtained in our work fully corresponds to the expected value of $E_{t r}$.

The luminescence bands in the visible region at 1.9$2.6 \mathrm{eV}$ (I-III) are detected in $\mathrm{BeO}: \mathrm{Mg}$ crystals (Fig. 1). The centers of long-wavelength luminescence should also be attributed to the presence of a magnesium impurity in the $\mathrm{BeO}$ lattice: the luminescence bands at $1.9-2.6 \mathrm{eV}$ are absent in undoped $\mathrm{BeO}$ crystals. The excitation spectra of photoluminescence bands at $2.4 \mathrm{eV}$ in BeO:Mg crystals at $T=77 \mathrm{~K}$ were studied earlier [29]; they were found to be localized in the energy range of $5.5-6.5 \mathrm{eV}$. It should be noted that it is in this energy region that luminescence excitation spectra of Flike centers are usually located, the basis of which is the presence of an anion vacancy in their composition (see, for example, review [26] and references therein). The determination of the microscopic nature of this luminescence center requires further theoretical studies. However, the experimental data obtained make it possible to discuss, as one of the possible models, an impurity complex consisting of an impurity magnesium ion near the anion vacancy. The set of experimental facts indicates that the luminescence of $\mathrm{BeO}: \mathrm{Mg}$ in the visible region should be attributed to intracenter transitions in the impurity complex including the magnesium ion.

The absence of the 'freezing' effect of the luminescence in the bands at 1.9-2.6, 4.3-4.4, and 6.0-6.2 eV at $T=6 \mathrm{~K}$ (Fig. 1) indicates the efficient excitation of these bands in the band-to-band transition region and may indirectly indicate the participation of both centers in recombination processes leading ultimately to the excitation of luminescence in both bands at $T=6 \mathrm{~K}$.

Low-temperature thermally stimulated luminescence of $\mathrm{BeO}: \mathrm{Mg}$ crystals has similarities and differences with that of $\mathrm{BeO}$ and $\mathrm{BeO}: \mathrm{Zn}$. At a qualitative level, this result agrees with the data obtained earlier for the BeO:Zn crystal [32].

In all three crystalline systems $(\mathrm{BeO}, \mathrm{BeO}: \mathrm{Mg}$, and $\mathrm{BeO}: \mathrm{Zn}$ ), a peak at $85 \mathrm{~K}$ dominates in low-temperature $\mathrm{TL}$, the temperature position of which varies insignifi- 
cantly, and the parameters of the peak shape (amplitude, width at half-maximum) vary considerably with the introduction of isovalent impurities (Table 2). This points at two important circumstances: the capture centers that cause the peak at $85 \mathrm{~K}$ are intrinsic defects of the $\mathrm{BeO}$ lattice, and the introduction of isovalent impurities has only a disturbing effect on the parameters of this peak.

Despite the long history of the study of beryllium oxide crystals, the origin of these trapping centers remains unclear. For undoped $\mathrm{BeO}$, only the hole character of this peak and the absence of an explicit relationship between its presence and any of $\mathrm{BeO}$ defects are reliably found so far [23, 29]. Based on these facts, a hypothesis was made, still unconfirmed, that the TL peak at $85 \mathrm{~K}$ can be conditioned by the acquisition of mobility by self-trapped holes in $\mathrm{BeO}$ [26]. However, the amount of experimental data on the TL peak at $85 \mathrm{~K}$ in undoped $\mathrm{BeO}$ crystals is not sufficient to delve into the discussion of the nature of this peak.

The effect of isovalent impurities on the parameters of the TL peak at $85 \mathrm{~K}$ in doped crystals is explained in the framework of the model of the fluctuation rearrangement of the structure, which decreases the potential barrier [46-48]. For the magnesium impurity, such an effect was first observed in the present study, and for an isovalent zinc impurity, a similar effect was observed earlier [32]. This indicates a qualitatively identical effect of various isovalent impurities on the parameters of the TL peak at $85 \mathrm{~K}$. In quantitative terms, the parameters of the TL peak for BeO:Mg occupy an intermediate position between those for undoped $\mathrm{BeO}$ and $\mathrm{BeO}: \mathrm{Zn}$ (Table 2).

The most significant effect of isovalent impurities is observed in the variation of the spectral composition of low-temperature TL in $\mathrm{BeO}: \mathrm{Mg}$ and $\mathrm{BeO}: \mathrm{Zn}$ crystals. This indicates that, in both cases, the isovalent impurities $(\mathrm{Mg}$ and $\mathrm{Zn}$ ) in a beryllium oxide crystal cause an efficient recombination channel that competes with the excitation channels of the UV and VUV luminescence of $\mathrm{BeO}$ in recombination thermal activation processes. However, while preserving a set of characteristic features inherent in the main luminescence bands of $\mathrm{BeO}$ with isovalent impurities, the $\mathrm{BeO}: \mathrm{Zn}$ and $\mathrm{BeO}: \mathrm{Mg}$ crystals show certain differences. The data [30] indicate that the band at $6.0 \mathrm{eV}$ in $\mathrm{BeO}: \mathrm{Zn}$ is a consequence of the radiative relaxation of small-radius excitons bound to the zinc impurity, whose structure is similar to that of the $\mathrm{STE}_{1}$, the radiative decay of which causes the $\mathrm{BeO}$ band to have its intrinsic luminescence band at $6.7 \mathrm{eV}$. The luminescence band at 4.3-4.4 eV in $\mathrm{BeO}: \mathrm{Mg}$ can be attributed to magnesium-bound excitons with an $\mathrm{STE}_{2}$ structure, the radiative decay of which causes the intrinsic luminescence band of $\mathrm{BeO}$ at $4.9 \mathrm{eV}$.

The low-temperature TL of $\mathrm{BeO}$ and $\mathrm{BeO}: \mathrm{Mg}$ crystals manifests itself against a background of tunnel luminescence (Fig. 6). It is known [49] that the tunnel luminescence of $\mathrm{BeO}: \mathrm{Zn}$ crystals, as well as of $\mathrm{BeO}$ doped with heterovalent impurities of $\mathrm{B}$ or $\mathrm{Al}$, is caused by the interdefect tunneling recombination. This corresponds to a tunnel electron transfer from a relatively deep electronic center $\left(\mathrm{B}^{2+}, \mathrm{Al}^{2+}\right.$, or $\left.\mathrm{Zn}^{+}\right)$to a shallow trapped-hole center. The decay of tunnel luminescence occurs at a temperature when there is a thermally stimulated delocalization of charge carriers from the corresponding shallow trapped-hole center, which is accompanied by a peak of TL. It is seen from Fig. 6 that in an undoped $\mathrm{BeO}$ crystal, tunnel luminescence is observed as a TL peak at $85 \mathrm{~K}$ in the temperature range up to the dominant hole peak. This can indirectly indicate that the hole centers responsible for the TL peak at $85 \mathrm{~K}$ in undoped $\mathrm{BeO}$ crystals are one of the partners of the interdefect tunneling recombination. In doped $\mathrm{BeO}: \mathrm{Mg}$ crystals, the decay of low-temperature TL to the level corresponding to undoped $\mathrm{BeO}$ occurs in the temperature range of 200-250 K (Fig. 6). It can be concluded that the introduction of a magnesium impurity in $\mathrm{BeO}$ leads to the appearance of shallow trapping centers that contribute to the TL in the temperature range of $200-250 \mathrm{~K}$ or participate in the interdefect tunneling recombination.

\section{CONCLUSIONS}

A study was made of the low-temperature luminescence and thermally stimulated luminescence of $\mathrm{BeO}: \mathrm{Mg}$ single crystals over a temperature range from 6 to $380 \mathrm{~K}$ and energy intervals of $1.2-6.2 \mathrm{eV}$ (luminescence spectra) and 3.7-20 eV (luminescence excitation spectra). The obtained spectroscopic data indicate that the introduction of impurity magnesium ions into the lattice of beryllium oxide occurs in several different ways. The experimental data give grounds for discussing the presence of at least three different luminescence-active centers in $\mathrm{BeO}: \mathrm{Mg}$, caused by impurity magnesium ions. In the luminescence spectra, these centers appear as three new broad luminescence bands at 6.2-6.3, 4.3-4.4, and 1.9-2.6 eV.

The first two bands (VUV and UV bands) are interpreted as the radiative annihilation of a relaxed exciton bound to a magnesium impurity. By the combination of spectral-luminescent properties and temperature dependences, the impurity VUV and UV bands are compared with those for the intrinsic luminescence of $\mathrm{BeO}$ caused by the radiative annihilation of self-trapped excitons of two kinds: the band at $6.2-6.3 \mathrm{eV}$ of $\mathrm{BeO}: \mathrm{Mg}$ is compared with the band at $6.7 \mathrm{eV}\left(\mathrm{STE}_{1}\right)$ of $\mathrm{BeO}$, and the impurity band at $4.3-4.4 \mathrm{eV}$ is compared with the band at $4.9 \mathrm{eV}\left(\mathrm{STE}_{2}\right)$ of $\mathrm{BeO}$. Impurity VUV and UV luminescence in BeO:Mg crystals is efficiently excited in a wide band with $E_{\text {ex }}=9.6 \mathrm{eV}$ lying in the region of fundamental absorption of $\mathrm{BeO}$, but below the energy position of the first exciton maximum of $\mathrm{BeO}$. The most probable interpretation of the excitation mechanism is the transfer of the energy of electronic excitations by the migration of free excitons with subsequent excitation of the relaxed state of the exciton localized near the magnesium impurity. The origin of the second max- 
imum at $10.22 \mathrm{eV}$ in the excitation spectrum of impurity VUV and UV luminescence in $\mathrm{BeO}: \mathrm{Mg}$ crystals can be explained by two possible causes: instrumental reason (partially overlapping bands of intrinsic and impurity VUV luminescence) and/or electron energy transfer by migration of free excitons followed by excitation of the nonrelaxed state of an exciton localized around the magnesium impurity. In favor of the correct interpretation of the origin of impurity VUV and UV bands of luminescence in $\mathrm{BeO}: \mathrm{Mg}$, the following experimental facts additionally testify. For an impurity UV band at $4.3-4.4 \mathrm{eV}$ : first, this band is efficiently excited at low temperatures in the exciton region and in the bandto-band transition region; second, this band dominates in the spectra of the low-temperature $\mathrm{TL}$ of $\mathrm{BeO}: \mathrm{Mg}$, which corresponds to the well-known property of the band of intrinsic UV luminescence of $\mathrm{BeO}$, namely, its efficient excitation in the processes of electron and hole recombination. The set of spectral-luminescent properties of the impurity VUV band at $6.2-6.3 \mathrm{eV}$ in $\mathrm{BeO}: \mathrm{Mg}$ is comparable to that for the band at $6.0 \mathrm{eV}$ in $\mathrm{BeO}: \mathrm{Zn}$, which was previously identified as radiative annihilation of zinc-bound relaxed excitons [32].

The third luminescence band in the visible region is a superposition several elementary bands caused by intracenter transitions in an impurity complex including a magnesium ion. The center of long-wavelength luminescence at $1.9-2.6 \mathrm{eV}$ is efficiently excited by photons in the $\mathrm{BeO}$ transparency band. The individual bands of this superposition are manifested in X-ray luminescence at $T=6 \mathrm{~K}$, which enables the discussion of not only their excitation during band-to-band transitions, but also their participation in recombination processes.

The first study of the TL of $\mathrm{BeO}: \mathrm{Mg}$ single crystals in the temperature range of 6-380 K made it possible not only to determine experimentally the energy characteristics of the impurity states of magnesium ions in beryllium oxide, but also to reveal the strong effect of the isovalent magnesium impurity on the manifestation of the fluctuation rearrangement of the environment in the region of the transformation of self-trapped excitons in $\mathrm{BeO}: \mathrm{Mg}$.

\section{ACKNOWLEDGMENTS}

The authors are grateful to A.V. Kruzhalov and V.A. Pustovarov for interest in the work and discussion, M.N. Sarychev for help in low-temperature measurements, and V.A. Maslov for providing crystals of beryllium oxide for research.

The work was partially supported by Resolution № 211 of the Government of the Russian Federation (contract № 02.A03.21.0006, the key center of excellence 'Radiation and Nuclear Technologies') and the Ministry of Education and Science of the Russian Federation (the basic part of the state assignment for performing research for Ural State University).

\section{REFERENCES}

1. Ch. B. Lushchik and A.Ch. Lushchik, Defect Formation in Solids by Decay of Electronic Excitations (Nauka, Moscow, 1989) [in Russian].

2. Ch. B. Lushchik, Excitons (Nauka, Moscow, 1985), p. 362 [in Russian].

3. K. A. Kalder, T. N. Kärner, Ch. B. Lushchik, A.F. Malysheva, and R. V. Milenina, Zh. Prikl. Spektrosk. 25, 639 (1976).

4. T.N. Kärner, A.F. Malysheva, A.A. Maaros, and V. V. Myurk, Sov. Phys. Solid State 22, 684 (1980).

5. S. A. Dolgov, T. Kärner, A. Lushchik, A. Maaroos, S. Nakonechnyi, and E. Shablonin, Phys. Solid State 53, 1244 (2011).

6. W. Crookes, Proc. R. Soc. London 32, 206 (1881).

7. C. E. Mandeville and H. O. Albrecht, Phys. Rev. 94, 494 (1954).

8. H. O. Albrecht and C.E. Mandeville, Phys. Rev. 101, 1250 (1956).

9. Y. Uchida, R. Kato, and E. Matsui, J. Quant. Spectrosc. Rad. Transfer 2, 589 (1962).

10. S. B. Austerman, J. Am. Ceram. Soc. 46, 6 (1963).

11. H. W. Newkirk, D. K. Smith, and J. S. Kahn, Am. Mineral. 51, 141 (1966).

12. V. A. Maslov, G. M. Rylov, V. G. Mazurenko, A. V. Kruzhalov, and B. V. Shulgin, in Proceedings of the 6th International Conference on Crystals Growth, Moscow, 1980, p. 268.

13. C. W. Peterson and G.E. Palma, J. Opt. Soc. Am. 63, 387 (1973).

14. D. M. Roessler, W.C. Walker, and E. Loh, J. Phys. Chem. Solids 30, 157 (1969).

15. V. Y. Ivanov, V. A. Pustovarov, A. V. Kruzhalov, and B. V. Shulgin, Nucl. Instrum. Methods Phys. Res. A 282, 559 (1989).

16. J. L. Freeouf, Phys. Rev. B 7, 3810 (1973).

17. E. Feldbach, W. Laasch, D. Varding, and G. Zimmerer, Phys. Status Solidi B 170, 623 (1992).

18. V. Yu. Ivanov, V. A. Pustovarov, S. V. Gorbunov, and A. V. Kruzhalov, Phys. Solid State 36, 1436 (1994).

19. V.A. Pustovarov, V. Yu. Ivanov, M. Kirm, A. V. Kruzhalov, A. V. Korotaev, and G. Zimmerer, Phys. Solid State 43, 1233 (2001).

20. B. V. Shul'gin, A. V. Kruzhalov, I. N. Ogorodnikov, L. V. Viktorov, V. A. Maslov, Ch. Alexander, and D. W. Cooke, Zh. Prikl. Spektrosk. 49, 286 (1988).

21. I. N. Ogorodnikov, A. V. Kruzhalov, and V. Yu. Ivanov, in Proceedings of the International Conference SCINT95, Delft, 1995, p. 216.

22. Proceedings of 1st International Conference on Beryllium Oxide, Sydney, 1964, Ed. by R. Smith and J. P. Howe.

23. I. N. Ogorodnikov and A. V. Kruzhalov, Mater. Sci. Forum 239-241, 51 (1997).

24. A.V. Kruzhalov, I. N. Ogorodnikov, and S. V. Kudyakov, Russ. Phys. J. 39, 1067 (1996).

25. V. Yu. Ivanov, E. H. Fel'dbakh, S. V. Gorbunov, A. V. Kruzhalov, and I. L. Kuusmann, Sov. Phys. Solid State 30, 1572 (1988).

26. I. N. Ogorodnikov, V. Yu. Ivanov, and A. V. Kruzhalov, Phys. Solid State 36, 1748 (1994). 
27. V. A. Pustovarov, V.Yu. Ivanov, A. V. Kruzhalov, I. N. Ogorodnikov, G. N. Kulipanov, É.I. Zinin, M. Kirm, and G. Zimmerer, in Proceedings of the International Conference SCINT99, Moscow, 2000, p. 266.

28. J. Jesionek, Z.R. Grabowski, and Pr. Ośr, Bad.-Rozw. Techn. Telewiz. 3, 51 (1978).

29. I. N. Ogorodnikov, V. Yu. Ivanov, and A. V. Kruzhalov, Zh. Prikl. Spektrosk. 54, 605 (1991).

30. V. Yu. Ivanov, I. N. Antsygin, S. V. Gorbunov, A. V. Kruzhalov, and V. A. Maslov, Opt. Spectrosc. 64, 564 (1988)

31. I. N. Antsigin, S. V. Gorbunov, A.V. Kruzhalov, and B. V. Shulgin, Hyperfine Interact. 60, 881 (1990).

32. I. N. Ogorodnikov, M.D. Petrenko, and V. Yu. Ivanov, Opt. Mater. 62, 219 (2016).

33. S. A. Dolgov, V. Isakhanyan, T. Kärner, P. Liblik, A. Maaroos, and S. Nakonechnyi, Rad. Meas. 38, 699 (2004)

34. A. Lushchik, M. Kirm, I. Kudryavtseva, Ch. Lushchik, I. Martinson, V. Nagirnyi, and E. Vasil'chenko, Radiat. Eff. Defects Solids 157, 537 (2002).

35. T. N. Kärner, A. A. Maaroos, A.F. Malysheva, and B. T. Tazhigulov, Sov. Phys. Solid State 28, 1438 (1986).

36. T. Karner, S. A. Dolgov, V. Isakhanyan, A. Maaroos, and S. Nakonechnyi, Radiat. Eff. Defects Solids 158, 163 (2003)
37. S. A. Dolgov, V. Isakhanyan, T. Kärner, A. Maaroos, and S. Nakonechnyi, J. Phys.: Condens. Matter 15, 6871 (2003).

38. V. Issahanyan, T. Kärner, A. Maaroos, and S. Nakonechnyi, Phys. Status Solidi C 2, 426 (2005).

39. G. Zimmerer, Rad. Meas. 42, 859 (2007).

40. M. D. Petrenko, I. N. Ogorodnikov, and V. Yu. Ivanov, Rad. Meas. 90, 14 (2016).

41. M.D. Petrenko, I. N. Ogorodnikov, V. Yu. Ivanov, M. N. Sarychev, and I. I. Milman, Izv. Vyssh. Uchebn. Zaved., Fiz. 57, 66 (2014).

42. R. Chen, J. Electrochem. Soc. 116, 1254 (1969).

43. R. Chen, J. Appl. Phys. 40, 570 (1969).

44. R. Chen, J. Mater. Sci. 9, 345 (1974).

45. I. N. Ogorodnikov and A. V. Kruzhalov, J. Lumin. 72 74, 701 (1997)

46. I. N. Ogorodnikov, V.I. Kirpa, and A. V. Kruzhalov, Tech. Phys. 38, 404 (1993).

47. I. N. Ogorodnikov and A. V. Kruzhalov, Tech. Phys. 40, 556 (1995).

48. I. N. Ogorodnikov and A. V. Kruzhalov, Proc. SPIE 2967, 42 (1997).

49. I. N. Ogorodnikov, A. V. Kruzhalov, A. A. Nagornyi, and B. V. Shul'gin, Available from VINITI No. 3546V87 (Ural. Politekh. Inst., Sverdlovsk, 1987). http://hdl.handle.net/10995/20719 